\title{
Neutrophil-to-lymphocyte ratio predicts the severity of motor impairment in cerebral palsy children living at home and the rehabilitation center: A comparative study
}

\author{
KANYAKORN RIEWRUJA ${ }^{1,2}$, CHAVARIN AMARASE ${ }^{1}$, PHATCHARAPA OSATEERAKUN ${ }^{1}$, \\ SOARAWIT WEERASOPONE ${ }^{1}$, NOPPACHART LIMPAPHAYOM ${ }^{1}$ and SITTISAK HONSAWEK ${ }^{1,2}$ \\ ${ }^{1}$ Department of Orthopaedics, Faculty of Medicine, Chulalongkorn University, King Chulalongkorn Memorial Hospital, \\ Thai Red Cross Society; ${ }^{2}$ Department of Biochemistry, Osteoarthritis and Musculoskeleton Research Unit, \\ Faculty of Medicine, Chulalongkorn University, King Chulalongkorn Memorial Hospital, \\ Thai Red Cross Society, Bangkok 10330, Thailand
}

Received July 8, 2020; Accepted September 28, 2020

DOI: $10.3892 /$ br.2020.1370

\begin{abstract}
The aim of the present study was to investigate the neutrophil-to-lymphocyte ratio (NLR) level in children with cerebral palsy (CP) living at home or the rehabilitation center. The correlation of NLR with different severities of motor impairment was assessed. This was a single-center, cross-sectional, observational study. A total of $80 \mathrm{CP}$ children who were either living at home $(n=34)$ or at the rehabilitation center $(n=46)$ were included. Demographic characteristics, anthropometric parameters and complete blood counts were recorded, and the NLR values were calculated. The severity of motor impairment was evaluated and categorized according to the Gross Motor Functional Classification System (GMFCS) level. The mean age of CP participants was $8.52 \pm 1.92$ years. The percentage of children with CP who were malnourished (underweight, stunted and wasted) was higher amongst those at the rehabilitation center compared with those living at home. The mean NLR of children with CP in the rehabilitation center was significantly higher compared with the patients living at home $(\mathrm{P}=0.003)$. Participants from the rehabilitation center had severe motor impairment (GMFCS levels IV-V) and
\end{abstract}

Correspondence to: Professor Sittisak Honsawek, Department of Biochemistry, Osteoarthritis and Musculoskeleton Research Unit, Faculty of Medicine, Chulalongkorn University, King Chulalongkorn Memorial Hospital, Thai Red Cross Society, 1873 Rama IV Road Patumwan, Bangkok 10330, Thailand

E-mail: sittisak.h@chula.ac.th

Abbreviations: $\mathrm{BMI}$, body mass index; $\mathrm{CBC}$, complete blood count; CP, cerebral palsy, GMFCS, gross motor functional classification system; LMR, lymphocyte-to-monocyte count ratio; MMI, mild motor impairment; NLR, neutrophil-to-lymphocyte ratio; SMI, severe motor impairment

Key words: cerebral palsy, neutrophil-to-lymphocyte ratio, motor impairment significantly higher NLR values than those with mild motor impairments (GMFCS levels II-III; $\mathrm{P}=0.006$ ). However, there were no differences in NLR values in relation to severity of motor impairment in CP children living at home. CP children had some degree of neuroinflammation and systemic inflammation. NLR may be a potential simple inflammatory parameter that may be used to predict the severity of the motor impairment, particularly in CP children living at a rehabilitation center.

\section{Introduction}

Cerebral palsy (CP) is a heterogeneous disorder and there are several degrees of motor impairment and permanent non-progressive neurologic deficits due to the injury of the immature brain (1). CP is the most prevalent cause of disabilities in children. The overall global prevalence of $\mathrm{CP}$ is 2-3 per 1,000 live births (1). The motor disorders of CP include disturbances of sensation, perception, cognition, communication and behavior; and these symptoms are caused by epilepsy and secondary musculoskeletal disorders (2). Aside from the physical and mental disabilities, children with $\mathrm{CP}$ are often malnourished due to disruption of the enteric neural pathways resulting in problems swallowing, and as a result exhibit gastroesophageal reflux and difficulty in breathing (3). Previous studies have reported the negative effects of malnutrition on muscle strength, impairment of motor function and weakness of the respiratory muscle (4), pre-dispositions to congestive heart failure (5), impairments in wound healing and immune function, and increased risk of postoperative complications (6).

The classification of CP is based on the motor type and distribution including ataxia, athetoid, diplegia, double hemiplegia, hemiplegia and quadriplegia (3). The Gross Motor Function Classification System (GMFCS) is used in clinical practice (3). Studies have shown that a persistent and exacerbated inflammatory response in the central nervous system can cause neuronal damage $(7,8)$. To the best of our knowledge, there are no studies aimed at identifying inflammatory biomarkers that can indicate the severity of CP. 
Peripheral blood tests are routinely used in clinical practice. Several studies have reported that the neutrophil-to-lymphocyte ratio (NLR) and lymphocyte-to-monocyte ratio (LMR) may serve as biomarkers of an inflammatory response, and may be used as prognostic factors to predict the outcome or the severity of various malignancies (9), cardiovascular disease (10), systemic lupus erythematosus (11), hip fracture and polytrauma (12). Moreover, studies have demonstrated that NLR is associated with nutritional status in geriatric and cancer patients $(13,14)$.

The healthcare costs for CP children with co-morbidities are high. In Australia, the cost of taking care of a single CP child is $\$ 43,431$ per year (15). There are two primary means of providing healthcare for children with $\mathrm{CP}$ : Home-based procedures and rehabilitation center-based procedures. Home-based patients exhibit improved social acceptance, functioning, participation and physical health, emotional wellbeing and self-esteem, as well as family health; in addition, these patients do not need to spend a lot of time traveling to the doctor, and thus have lower transportation costs (15). However, the healthcare costs for these patients are higher compared to children living in a rehabilitation center.

As CP children may live in different settings, the aim of the present study was to investigate the physical growth, nutritional status and inflammatory predictors between children living at home and the rehabilitation center. It was hypothesized that $\mathrm{CP}$ children living at home would exhibit improved physical growth, nutritional status and lower inflammatory parameters when compared with $\mathrm{CP}$ children living in a rehabilitation center. The relationships between these parameters and the severity of the motor impairment in $\mathrm{CP}$ children were also examined.

\section{Materials and methods}

Ethics. The study protocol used in the present study conformed to the ethical standards outlined in the Declaration of Helsinki and was approved by the Institutional Review Board on Human Research of the Faculty of Medicine, Chulalongkorn University. Informed consent was obtained from one of the parents or the legal guardian of the children, as well as from the child prior to his/her participation in the study.

Study participants. A total of $86 \mathrm{CP}$ children were enrolled in a cross-sectional analytical study that was performed between June and December 2013. A total of 6 children were excluded as they had a history of gastrostomy $(n=2)$, osteotomy around the knee $(n=2)$, or were infections during the screening period $(n=2)$. A total of 80 children with CP (45 males and 35 females) were eligible for analysis. The mean age in this study population was $8.52 \pm 1.92$ years. These children were recruited from either a home-living setting $(n=34)$ or a rehabilitation center $(n=46)$. The home-living participants were those who lived at home and visited the rehabilitation center during office hours. Participants who lived at the rehabilitation center for at least 9 months were enrolled into the study.

Determination of clinical parameters. For the anthropometric measurements in the present study, the body weight was obtained and the height was calculated using Stevenson's recommended formula (16). The height $(\mathrm{cm})$ was measured while in a sitting position from the knee to the floor. This measurement was taken 3 times, and the mean height was used. The body mass index (BMI) was calculated. To evaluate the nutritional status of the children, the anthropometric indices, including weight-for-age, height-for-age and weight-for-height, were used to calculate the $\mathrm{z}$ score based on the World Health Organization reference population median (17). Z-scores $>2$ standard deviations lower than the mean, for weight-for-age, height-for-age and weight-for-height, were considered as underweight, stunted and wasted, respectively.

The motor function for all CP children was evaluated and assigned according to the Gross Motor Function Classification System (GMFCS) level by certified physical therapists (18). The severity levels of motor impairment were divided into two groups: Mild motor impairment (GMFCS levels I-III) and severe motor impairment (GMFCS levels IV-V).

Peripheral blood counts were obtained from all participants as part of routine analysis. An automated hematology analyzer (Advia 2120 Hematology system; Siemens Healthineers) was utilized to obtain the complete blood count (CBC). Neutrophil and lymphocyte counts were extracted from the differential blood pictures. The NLR was calculated by dividing the absolute count of neutrophils by the number of lymphocytes from the CBCs. Additionally, the LMR was determined by dividing the absolute number of lymphocytes to the number of the monocytes.

Statistical analysis. Statistical analysis was performed using SPSS version 22.0 (IBM Corp.). Continuous data are presented as the mean \pm standard error of the mean. Categorical data are summarized as the frequency and percentages. Comparisons of the frequencies of various demographic variables between the two groups were performed using a $\chi^{2}$ test. The distributions of the continuous data were examined using a Q-Q plot, Shapiro-Wilk's test and a Kolmogorov-Smirnov test. To compare the means between the two groups, an unpaired Student's t-test was used for variables that were normally distributed. A Mann-Whitney U test was used for variables that did not have a normal distribution. For comparisons between $>2$ groups of variables, a Kruskal-Wallis one-way ANOVA with a Dunn's post hoc test was used for all pairwise comparisons. Pearson's and Spearman's correlation analysis were used to examine the relationship between variables. $\mathrm{P}<0.05$ was used to indicate a statistically significant difference.

\section{Results}

The participants were divided into two groups, those living at home and those living in the rehabilitation center. The clinical characteristics of the participants are shown in Table I. There were no significant differences in the clinical characteristics between the two groups of children. Diplegic CP was the most common type of CP amongst participants living at home and the rehabilitation center. The severity of the motor impairment was categorized by GMFCS levels. In both care settings, the children had mild and severe motor impairments.

For anthropometric parameters, the height, weight and BMI were not significantly different between the children living at 
Table I. Clinical characteristics of CP children living at home or the rehabilitation center.

\begin{tabular}{|c|c|c|c|}
\hline Characteristics & Living at home, $\mathrm{n}(\%)$ & Living at rehabilitation centre, n (\%) & P-value \\
\hline Total & 34 & 46 & \\
\hline \multicolumn{4}{|l|}{ Sex } \\
\hline Male & $18(52.9)$ & $27(58.7)$ & 0.18 \\
\hline Female & $16(47.1)$ & $19(41.3)$ & 0.612 \\
\hline \multicolumn{4}{|l|}{ CP type } \\
\hline Ataxia & $1(2.9)$ & $0(0)$ & - \\
\hline Athetoid & $4(11.8)$ & $4(8.7)$ & 1 \\
\hline Diplegia & $19(55.9)$ & $33(71.7)$ & 0.052 \\
\hline Double hemiplegia & $1(2.9)$ & $1(2.2)$ & 1 \\
\hline Hemiplegia & $1(2.9)$ & $5(10.9)$ & 0.102 \\
\hline Quadriplegia & $8(23.5)$ & $3(6.5)$ & 0.132 \\
\hline \multicolumn{4}{|l|}{ GMFCS level } \\
\hline MMI & $16(47.1)$ & $28(60.9)$ & 0.07 \\
\hline Level II & $3(8.8)$ & $6(13)$ & 0.317 \\
\hline Level III & $13(38.2)$ & $22(47.9)$ & 0.128 \\
\hline SMI & $18(52.9)$ & $18(39.1)$ & 1 \\
\hline Level IV & $11(32.4)$ & $15(32.6)$ & 0.433 \\
\hline Level V & 7 (20.6) & $3(6.5)$ & 0.206 \\
\hline \multicolumn{4}{|l|}{ Malnutrition } \\
\hline Underweight & $12(35.3)$ & $19(41.3)$ & 0.209 \\
\hline Stunted & $17(50)$ & $25(54.3)$ & 0.217 \\
\hline Wasted & $3(8.8)$ & 8 (17.4) & 0.132 \\
\hline
\end{tabular}

CP, cerebral palsy; GMFCS, gross motor functional classification system; MMI, mild motor impairment; SMI, severe motor impairment.

home and the rehabilitation center. However, the percentage of underweight, stunted and wasted participants was higher amongst children living at the rehabilitation center compared with those living at home (Table I). The weight-for-height percentiles were strongly correlated with $\mathrm{BMI}$ in $\mathrm{CP}$ children $(r=0.919, \mathrm{P}<0.001$; Fig. 1). The distribution of weight-for-height percentiles with stacking of each GMFCS level demonstrated left shifting, particularly in children living at the rehabilitation center (Fig. 2).

The CBC analysis showed that total white blood cell counts, neutrophil counts and the NLR values were significantly greater in the $\mathrm{CP}$ children at the rehabilitation center compared with those living at home $(\mathrm{P}<0.05$; Table II). There was a direct association between the total white blood cell count and the NLR ( $\mathrm{r}=0.446, \mathrm{P}<0.001)$. However, NLR was inversely correlated with LMR in CP children, as illustrated in Fig. 3 ( $r=-0.699, \mathrm{P}<0.001)$.

Overall, the NLR of the children in the rehabilitation center was significantly higher than those living at home ( $\mathrm{P}=0.003$; Table II). Additionally, the NLR was significantly higher in children with severe motor impairment $(\mathrm{P}=0.001$; Table III; Fig. 4). In the rehabilitation center, the NLR values between mild and severe motor impairments were statistically different $(\mathrm{P}=0.006)$ and the proportion of children with GMFCS level $\mathrm{V}$ was greater than those with levels II and III $(\mathrm{P}=0.021$ and $\mathrm{P}=0.04$, respectively; Table III; Fig. 4). However, the NLR values were not significantly different

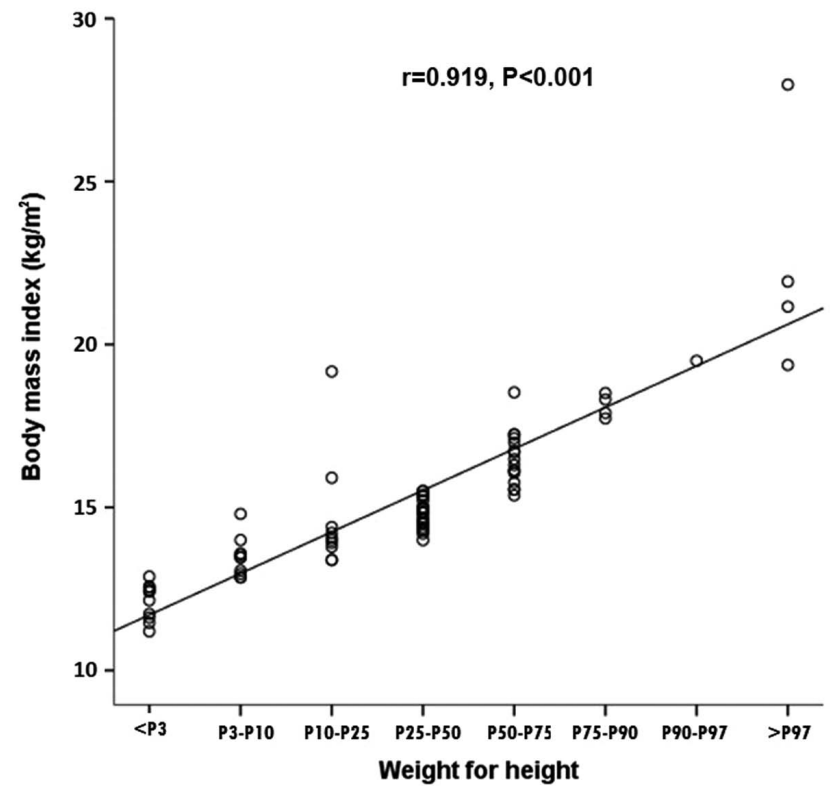

Figure 1. Scatter diagram and correlation analysis of body mass index and weight-for-height percentiles in children with cerebral palsy. Body mass index was directly associated with weight-for-height; $P$, percentile.

amongst children based on severity of motor impairment. NLR was significantly positively correlated with GMFCS level ( $r=0.467, \mathrm{P}=0.001$; Fig. 5). 
Table II. Comparison of anthropometric and biochemical parameters of study samples compared between children with CP living at home or the rehabilitation center.

\begin{tabular}{lccc}
\hline Characteristics & $\begin{array}{c}\text { Living at home, } \mathrm{n}=34 \\
\text { mean } \pm \text { SEM }\end{array}$ & $\begin{array}{c}\text { Living at rehabilitation centre, } \mathrm{n}=46 \\
\text { mean } \pm \text { SEM }\end{array}$ & P-value \\
\hline Age, years & $8.41 \pm 0.4$ & $8.52 \pm 0.28$ & 0.819 \\
Height, $\mathrm{cm}$ & $115.21 \pm 2.73$ & $114.52 \pm 1.79$ & 0.828 \\
Weight, $\mathrm{kg}$ & $22.14 \pm 1.13$ & $21.64 \pm 1.03$ & 0.778 \\
BMI, $\mathrm{kg} / \mathrm{m}^{2}$ & $15.46 \pm 0.41$ & $15.02 \pm 0.4$ & 0.376 \\
Haemoglobin, $\mathrm{g} / \mathrm{dl}$ & $13.06 \pm 0.16$ & $12.76 \pm 0.15$ & 0.18 \\
Haematocrit, $\%$ & $38.77 \pm 0.46$ & $38.25 \pm 0.39$ & 0.386 \\
White blood cells, $\mathrm{x} 10^{6} / 1$ & $7,785.59 \pm 339.46$ & $8,728.04 \pm 297.02$ & $0.022^{\mathrm{a}}$ \\
Neutrophils, $\mathrm{x} 10^{6} / 1$ & $3,726.5 \pm 238.25$ & $4,791.3 \pm 257.5$ & $0.002^{\mathrm{b}}$ \\
Lymphocytes, $\mathrm{x} 10^{6} / 1$ & $3,111.8 \pm 144.34$ & $2,939.13 \pm 130.05$ & 0.38 \\
Monocytes, $\mathrm{x} 10^{6} / 1$ & $455.6 \pm 31.34$ & $488.7 \pm 27.12$ & 0.273 \\
Neutrophil-to-lymphocyte ratio & $1.29 \pm 0.1$ & $1.81 \pm 015$ & $0.003^{\mathrm{b}}$ \\
Lymphocyte-to-monocyte ratio & $7.82 \pm 0.62$ & $6.66 \pm 0.41$ & 0.106 \\
\hline
\end{tabular}

a $\mathrm{P}<0.05$, ${ }^{\mathrm{P}}<0.01$. BMI, body mass index; $\mathrm{CP}$, cerebral palsy; SEM, standard error of the mean.

A

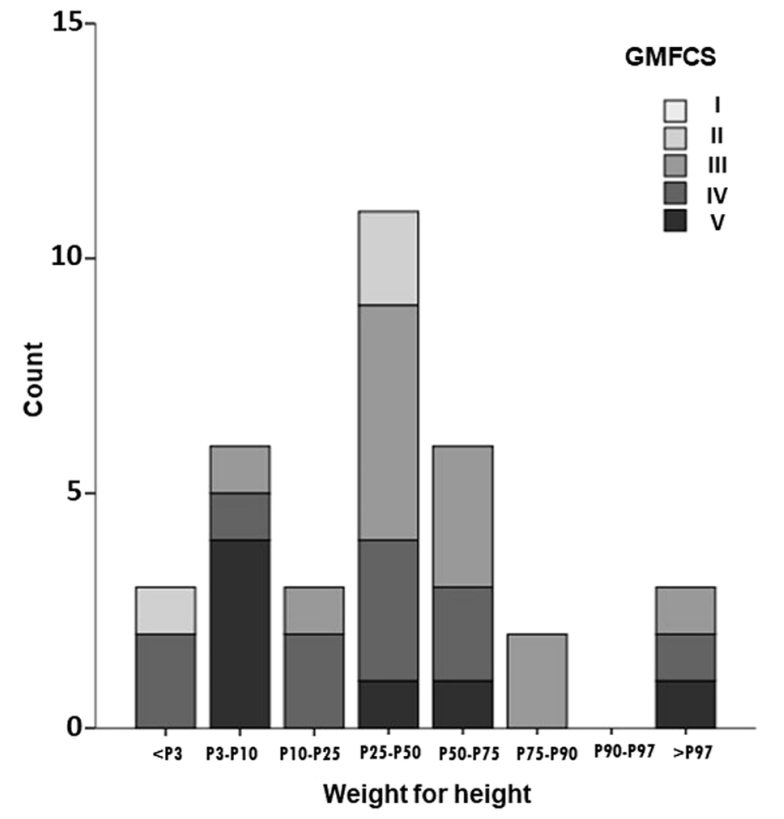

B

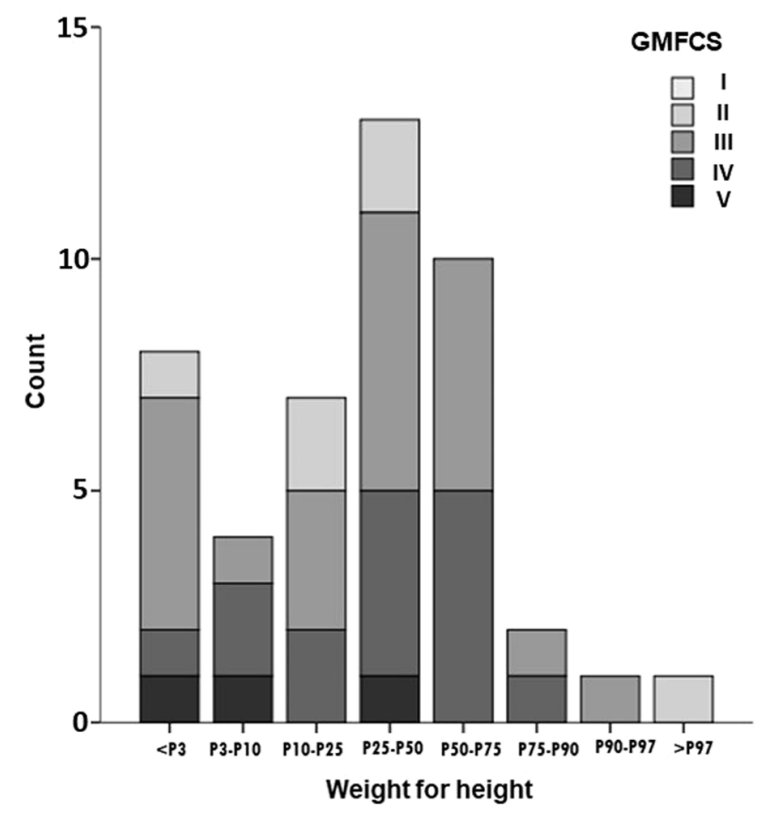

Figure 2. Histogram of weight-for-height percentiles of children with cerebral palsy. (A) Living at home. (B) Living at the rehabilitation center. Frequency of children with each GMFCS level is stacked on top of each other. GMFCS, gross motor functional classification system; P, percentile.

\section{Discussion}

The aim of the present study was to evaluate the physical growth, nutritional status, and the inflammatory parameters of NLR and LMR between CP children living at home compared with those living in a rehabilitation center. The results showed that almost half of the children had one form of malnutrition. The most common type of malnutrition was stunted growth (50\% of children at home and $54.3 \%$ of children at the center), followed by being underweight (35.3\% of children at home and $41.3 \%$ of children at center) and wasted (8.8\% of children at home and $17.4 \%$ of children at center), in agreement with a previous study (19).

Henderson et al (20) reported that residential care children showed improved growth and nutrition scores, lower height $\mathrm{Z}$ scores, similar weight and muscle mass, and greater subcutaneous fat $\mathrm{Z}$ scores than children living at home. In contrast, the results of the present study showed higher percentages of all forms of malnutrition in $\mathrm{CP}$ children living at the rehabilitation center compared with those living at home.

In routine medical practice, $\mathrm{CBC}$ and differentiation analysis are commonly used $(21,22)$. In the present study, the severity of 
A

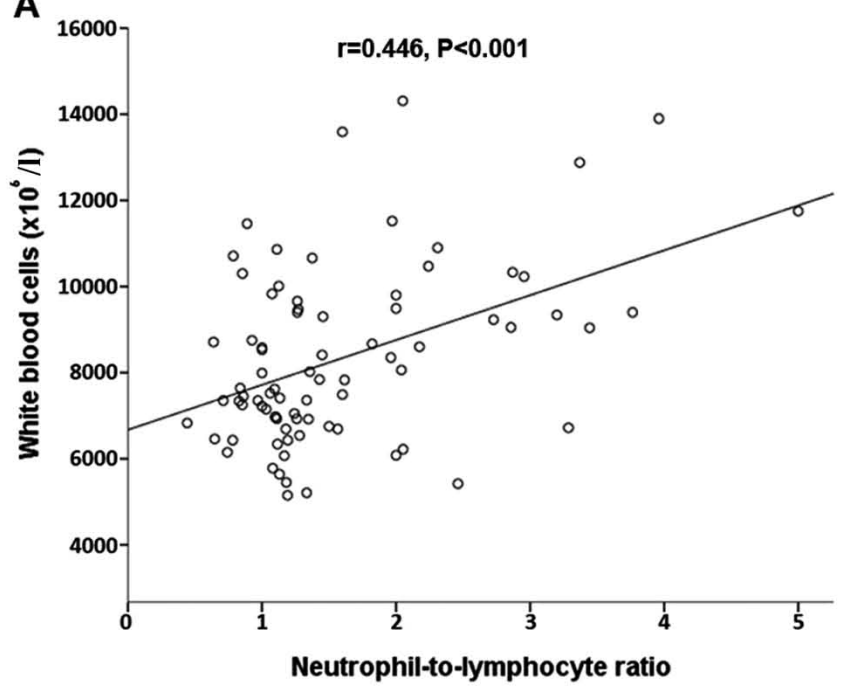

B

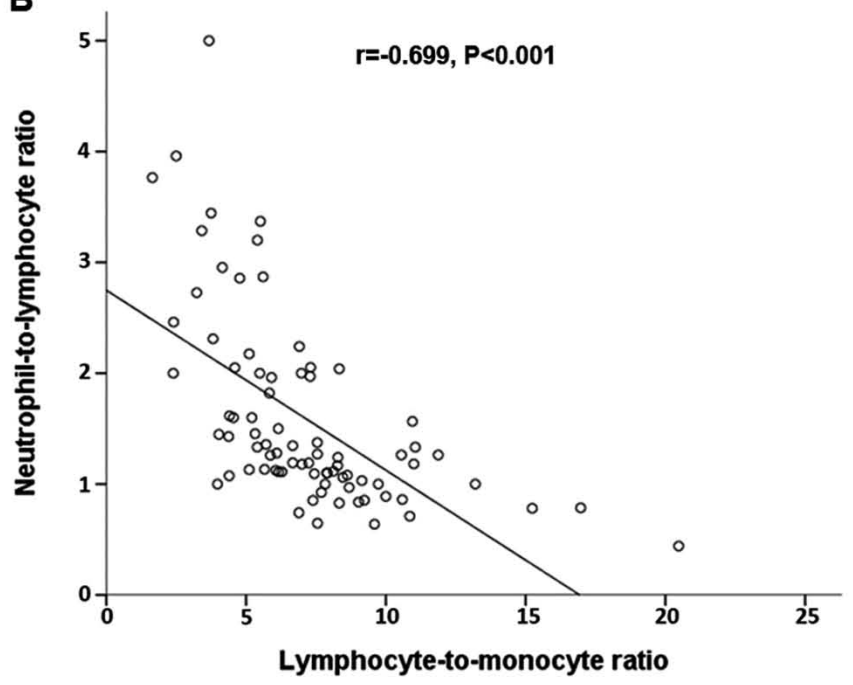

Figure 3. Scatter diagram and correlation analysis of inflammatory parameters in children with cerebral palsy. (A) Total white blood cell counts were positively correlated with NLR. (B) NLR was inversely correlated with lymphocyte-to-monocyte ratio. NLR, neutrophil-to-lymphocyte ratio.

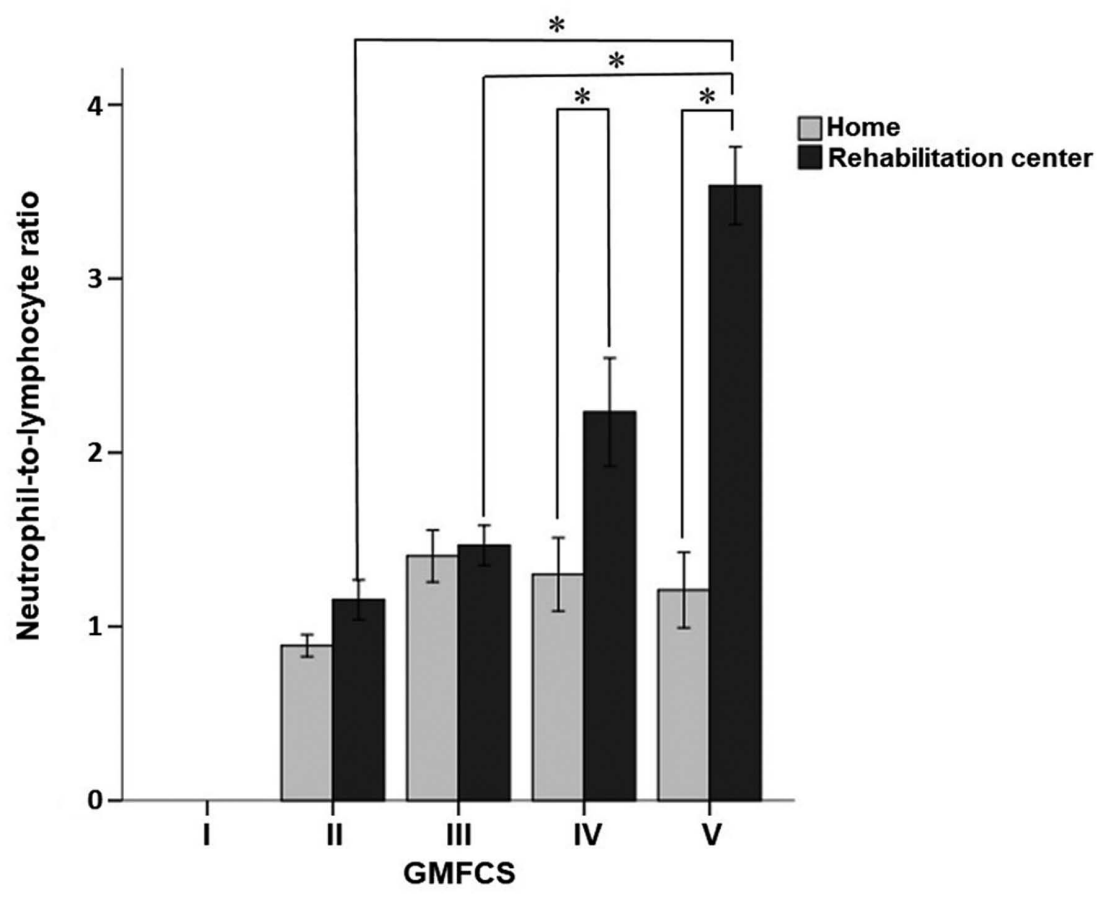

Figure 4. Clustered bar graph of the neutrophil-to-lymphocyte ratio for each GMFCS level between children living at home (gray) and at the rehabilitation center (black). ${ }^{*} \mathrm{P}<0.05$. GMFCS, gross motor functional classification system.

the motor impairments was associated with higher NLR values, particularly in CP children living at the rehabilitation center. NLR values were significantly higher in CP children with severe motor impairment in the rehabilitation center.

NLR is easy to calculate and can provide useful information. Increases in NLR are indicative of systemic inflammation and physiological stress responses, including an increase in neutrophil counts, a decrease in lymphocyte counts, or both (23). Recently, NLR has been shown to be a good prognostic parameter for assessment of various diseases and was correlated with the treatment or operational outcomes of several clinical conditions, including gastric, liver and colorectal cancer (24-26). Additionally, NLR is positively correlated with several biomarkers of cancer, such as carbohydrate antigen 19-9 and carcinoembryonic antigen, and was associated with advanced stage malignancies $(27,28)$, and overall survival and mortality for various diseases $(29,30)$.

Persistent elevation in inflammation-related proteins during the first two postnatal weeks is associated with the diagnosis of $\mathrm{CP}$, and this pattern of expression was also observed in severely cognitively impaired children (31). CP is a neurodevelopmental disorder and is attributed to injury in the developing brain. Various animal models of $\mathrm{CP}$ have shown that the injury to the central nervous system is due to hypoxia-ischemia and 
Table III. Comparison of NLR and motor impairment severity between children with CP living at home-living and those living at a rehabilitation center.

\begin{tabular}{|c|c|c|c|}
\hline Characteristics & $\begin{array}{l}\text { Living at home, } \mathrm{n}=34 \\
\mathrm{n}(\text { mean } \pm \mathrm{SEM})\end{array}$ & $\begin{array}{l}\text { Living at rehabilitation centre, } \mathrm{n}=46 \\
\mathrm{n}(\text { mean } \pm \text { SEM })\end{array}$ & P-value \\
\hline \multicolumn{4}{|l|}{ MMI } \\
\hline GMFCS level II & $3(0.89 \pm 0.63)$ & $6(1.15 \pm 0.11)$ & 0.121 \\
\hline GMFCS level III & $13(1.41 \pm 0.15)$ & $22(1.47 \pm 0.11)$ & 0.759 \\
\hline Total & $16(1.31 \pm 0.13)$ & $28(1.4 \pm 0.1)$ & 0.38 \\
\hline \multicolumn{4}{|l|}{ SMI } \\
\hline GMFCS level IV & $11(1.3 \pm 0.21)$ & $15(2.23 \pm 0.31)$ & $0.014^{\mathrm{a}}$ \\
\hline GMFCS level V & $7(1.21 \pm 0.22)$ & $3(3.53 \pm 0.22)$ & $0.017^{\mathrm{a}}$ \\
\hline Total & $18(1.26 \pm 0.15)$ & $18(2.45 \pm 0.29)$ & $0.001^{\mathrm{b}}$ \\
\hline Overall & $34(1.29 \pm 0.1)$ & $46(1.81 \pm 0.15)$ & $0.003^{\mathrm{b}}$ \\
\hline P (MMI/SMI) & 0.437 & $0.006^{\mathrm{b}}$ & \\
\hline P (GMFCS $)$ & 0.194 & $0.01^{\mathrm{b}}$ & \\
\hline
\end{tabular}

P-values for differences between the home-living and rehabilitation center. ${ }^{\mathrm{a}} \mathrm{P}<0.05$, ${ }^{\mathrm{b}} \mathrm{P}<0.01$. CP, cerebral palsy, GMFCS, Gross Motor Function Classification System; MMI, mild motor impairment, SMI, severe motor impairment; SEM, standard error of the mean.

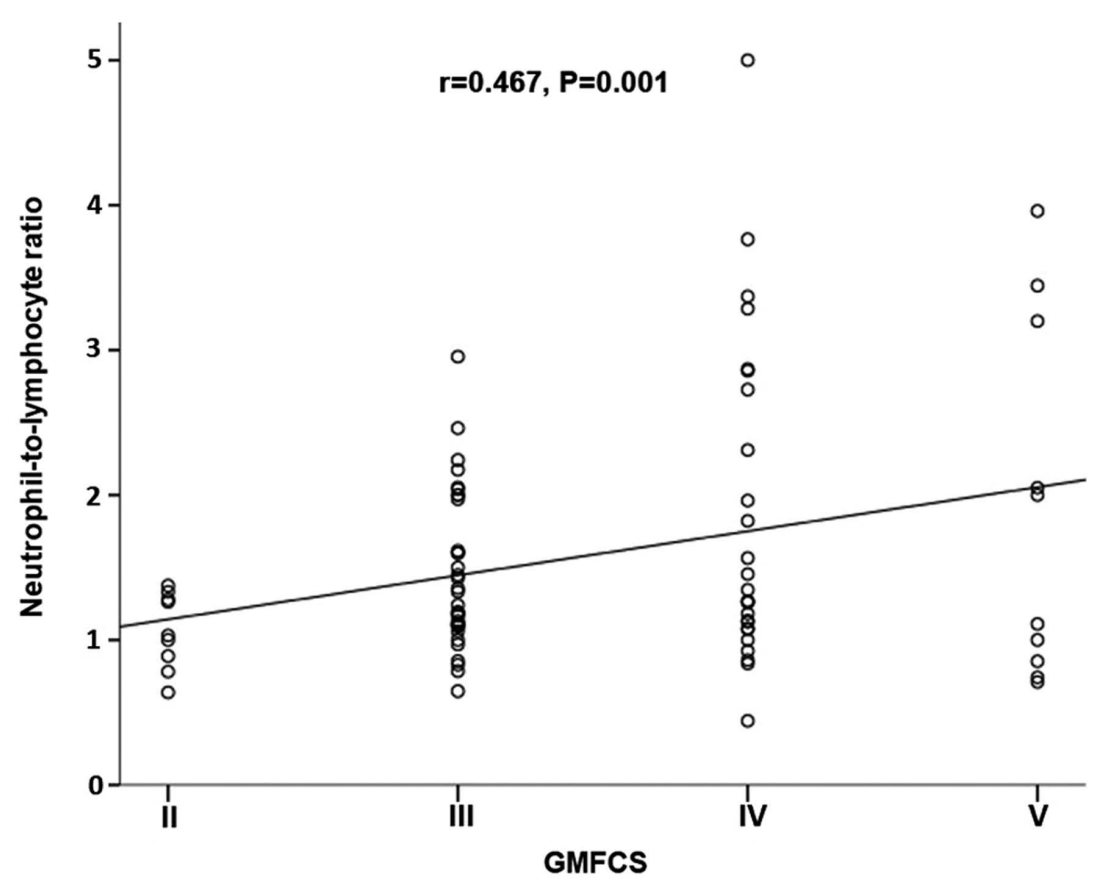

Figure 5. Scatter diagram and correlation analysis of NLR and GMFCS of the children with cerebral palsy living at the rehabilitation center. NLR was positively correlated with GMFCS. GMFCS, gross motor functional classification system; NLR, neutrophil-to-lymphocyte ratio.

inflammation in the brain (32). Furthermore, elevated inflammatory response-associated proteins may reflect the ongoing damage of the brain cells resulting in brain dysfunction (33).

Over half of neuroanatomical abnormalities in CP patients are white matter injuries, cystic periventricular leukomalacia and periventricular hemorrhagic infarction (34). The ELGAN cohort found that systemic inflammation was associated with white matter abnormalities (35). Inflammatory cytokines and inflammation related proteins are present during the neonatal period $(36,37)$. Additionally, levels of IL-1 $\beta$, IL-6, TNF and CXCL8/IL-8 in children with CP are persistently elevated (8).
Unfortunately, the markers mentioned above are rarely used in routine medical practices, and only in research. Thus, our proposed low cost, accessible inflammatory predictor, NLR, may be an improved prognostic parameter for CP; however, additional studies are required to confirm these results.

The present study has some limitations. First, this was a cross-sectional study. Therefore it was not possible to determine a cause-effect relationship. Second, a healthy control group was not available for comparison. Third, the sample size was too small, and thus made identification of significant differences between groups difficult. Finally, it is possible that 
the environment, family participation and emotional stress may be different between the two groups, and this may affect the overall quality of life of CP children.

In conclusion, a high NLR value was associated with severe motor impairment in children with $\mathrm{CP}$, particularly those living in rehabilitation centers. These results suggest that NLR may be used as a prognostic predictor of severe motor impairment. However, further studies on the value and relevance of NLR are required to ascertain whether it can be used to predict treatment and/or surgical outcomes, as well as mortality and survival amongst $\mathrm{CP}$ children.

\section{Acknowledgements}

The authors would also like to thank Ms. Pirapon June Ohata, HIV-NAT, Thai Red Cross AIDS Research Center, Bangkok, Thailand for reviewing and proof-reading the manuscript.

\section{Funding}

This study was financially supported by the Osteoarthritis and MusculoskeletonResearchUnit,theRatchadapiseksompotchFund, Chulalongkorn University (grant no. CU_GR_63_95_30_02) and the Prince Mahidol Award Youth Program, Prince Mahidol Award Foundation.

\section{Availability of data and materials}

The datasets used and/or analyzed during the present study are available from the corresponding author on reasonable request.

\section{Authors' contributions}

$\mathrm{KR}, \mathrm{CA}, \mathrm{PO}, \mathrm{SW}, \mathrm{NL}$ and $\mathrm{SH}$ conceived and designed the experiments. KR, CA, PO, SW, NL and SH performed the experiments and analyzed the data. $\mathrm{CA}, \mathrm{NL}$ and $\mathrm{SH}$ provided the materials and analytical tools. CA, PO, SW and NL recruited the participants, obtained the written informed consents and collected the clinical data. KR and SH wrote and revised the manuscript. All authors have read and approved the final manuscript.

\section{Ethics approval and consent to participate}

The study protocol used in the present study conformed to the ethical standards outlined in the Declaration of Helsinki and was approved by the Institutional Review Board on Human Research of the Faculty of Medicine, Chulalongkorn University. Informed consent was obtained from one of the parents or the legal guardian, as well as from the child prior to his/her participation in the study.

\section{Patient consent for publication}

Not applicable.

\section{Competing interests}

The authors declare that they have no competing interests.

\section{References}

1. Rattanatharn R and Siriphaosuwankul W: Back and hip muscles with EMG biofeedback training in diplegic cerebral palsy to improve balance and gait: A randomized control trial. Chula Med J 63: 31-39, 2019.

2. Mahasup P and Kanchanomai S: Comparison of lower extremity range of motion during walking between children with cerebral palsy and normal children. Chula Med J 63: 171-177, 2019.

3. Gulati S and Sondhi V: Cerebral palsy: An overview. Indian J Pediatr 85: 1006-1016, 2018.

4. Kuperminc MN and Stevenson RD: Growth and nutrition disorders in children with cerebral palsy. Dev Disabil Res Rev 14: 137-146, 2008.

5. Viart P: Hemodynamic findings in servere protein-calorie malnutrition. Am J Clin Nutr 30: 334-348, 1977.

6. Cross MB, Yi PH, Thomas CF, Garcia J and Della Valle CJ: Evaluation of malnutrition in orthopaedic surgery. J Am Acad Orthop Surg 22: 193-199, 2014.

7. Fleiss $B$ and Gressens P: Tertiary mechanisms of brain damage: A new hope for treatment of cerebral palsy? Lancet Neurol 11: 556-566, 2012.

8. Magalhaes RC, Moreira JM, Lauar AO, da Silva AAS, Teixeira AL and E Silva ACS: Inflammatory biomarkers in children with cerebral palsy: A systematic review. Res Dev Disabil 95: 103508, 2019.

9. Templeton AJ, McNamara MG, Šeruga B, Vera-Badillo FE, Aneja P, Ocaña A, Leibowitz-Amit R, Sonpavde G, Knox JJ, Tran B, et al: Prognostic role of neutrophil-to-lymphocyte ratio in solid tumors: A systematic review and Meta-analysis. J Natl Cancer Inst 106: dju124, 2014.

10. Afari ME and Bhat T: Neutrophil to lymphocyte ratio (NLR) and cardiovascular diseases: An update. Expert Rev Cardiovasc Ther 14: 573-577, 2016.

11. Wang L, Wang C, Jia X, Yang $M$ and Yu J: Relationship between Neutrophil-to-lymphocyte ratio and systemic lupus erythematosus: A meta-analysis. Clinics (Sao Paulo) 75: e1450, 2020.

12. Alexandru L, Haragus H, Deleanu B, Timar B, Poenaru DV and Vlad DC: Haematology panel biomarkers for humeral, femoral, and tibial diaphyseal fractures. Int Orthop 43: 1567-1572, 2019.

13. Kaya T, Açıkgöz SB, Yıldırım M, Nalbant A, Altaş AE and Cinemre H: Association between neutrophil-to-lymphocyte ratio and nutritional status in geriatric patients. J Clin Lab Anal 33: e22636, 2019.

14. Sato Y, Gonda K, Harada M, Tanisaka Y, Arai S, Mashimo Y, Iwano H, Sato H, Ryozawa S, Takahashi T, et al: Increased Neutrophil-to-lymphocyte ratio is a novel marker for nutrition, inflammation and chemotherapy outcome in patients with locally advanced and metastatic esophageal squamous cell carcinoma. Biomed Rep 7: 79-84, 2017.

15. Sharif Azar E, Ravanbakhsh M, Torabipour A, Amiri E and Haghighyzade MH: Home-based versus center-based care in children with cerebral palsy: A cost-effectiveness analysis. J Med Life 8: 245-251, 2015.

16. Stevenson RD: Use of segmental measures to estimate stature in children with cerebral palsy. Arch Pediatr Adolesc Med 149: 658-662, 1995 .

17. de Onis M and Blössner M: The world health organization global database on child growth and malnutrition: Methodology and applications. Int J Epidemiol 32: 518-526, 2003.

18. CanChild: Gross Motor Function Classification System-Expanded and Revised (GMFCS-E\&R). CanChild, Hamilton, ON, 2019. https://canchild.ca/en/resources/42-gross-motor-function-classification-system-expanded-revised-gmfcs-e-r. Accessed September 30, 2020.

19. Khan S, Zaheer S and Safdar NF: Determinants of stunting, underweight and wasting among children $<5$ years of age: Evidence from 2012-2013 Pakistan demographic and health survey. BMC Public Health 19: 358, 2019.

20. Henderson RC, Grossberg RI, Matuszewski J, Menon N, Johnson J, Kecskemethy HH, Vogel L, Ravas R, Wyatt M, Bachrach SJ and Stevenson RD: Growth and nutritional status in residential center versus home-living children and adolescents with quadriplegic cerebral palsy. J Pediatr 151: 161-166, 2007.

21. Kurt-Mangold ME, Grieme CV, Krasowski MD and Rosenthal NS: Clinical utility of ordered pathology blood smear reviews-an overused resource? Clin Lab 64: 99-104, 2018. 
22. Barnes PW, McFadden SL, Machin SJ and Simson E: The international consensus group for hematology review: Suggested criteria for action following automated CBC and WBC differential analysis. Lab Hematol 11: 83-90, 2005.

23. Zahorec R: Ratio of neutrophil to lymphocyte Counts-rapid and simple parameter of systemic inflammation and stress in critically ill. Bratisl Lek Listy 102: 5-14, 2001 (In En, Slovak).

24. Li H, Zhao Y and Zheng F: Prognostic significance of elevated preoperative neutrophil-to-lymphocyte ratio for patients with colorectal cancer undergoing curative surgery: A Meta-analysis. Medicine (Baltimore) 98: e14126, 2019.

25. Wang Y, Peng C, Cheng Z, Wang X, Wu L, Li J, Huang C, Guo $\mathrm{Q}$ and Cai $\mathrm{H}$ : The prognostic significance of preoperative Neutrophil-lymphocyte ratio in patients with hepatocellular carcinoma receiving hepatectomy: A systematic review and meta-analysis. Int J Surg 55: 73-80, 2018.

26. Nakamura N, Kinami S, Tomita Y, Miyata T, Fujita H, Takamura H, Ueda N and Kosaka T: The neutrophil/lymphocyte ratio as a predictor of successful conversion surgery for stage IV gastric cancer: A retrospective study. BMC Cancer 20: 363, 2020

27. Tang $\mathrm{H}, \mathrm{Lu} \mathrm{W}, \mathrm{Li} \mathrm{B}, \mathrm{Li} \mathrm{C}, \mathrm{Xu} \mathrm{Y}$ and Dong J: Prognostic significance of neutrophil-to-lymphocyte ratio in biliary tract cancers: A systematic review and Meta-analysis. Oncotarget 8: 36857-36868, 2017.

28. Tang H, Li B, Zhang A, Lu W, Xiang C and Dong J: Prognostic significance of Neutrophil-to-lymphocyte ratio in colorectal liver metastasis: A systematic review and Meta-analysis. PLoS One 11: e0159447, 2016.

29. Kuang ZS, Yang YL, Wei W, Wang JL, Long XY, Li KY, Li KY, Tong CY, Sun Z and Song ZJ: Clinical characteristics and prognosis of community-acquired pneumonia in autoimmune disease-induced immunocompromised host: A retrospective observational study. World J Emerg Med 11: 145-151, 2020.

30. Krishnan A, Hsu J, Ha JS, Broderick SR, Shah PD, Higgins RS, Merlo CA and Bush EL: Elevated neutrophil to lymphocyte ratio is associated with poor long-term survival and graft failure after lung transplantation. Am J Surg: Apr 18, 2020 (Epub ahead of print).
31. O'Shea TM, Allred EN, Kuban KC, Dammann O, Paneth N, Fichorova R and Hirtz D, Leviton A; Extremely Low Gestational Age Newborn (ELGAN) Study Investigators: Elevated concentrations of Inflammation-related proteins in postnatal blood predict severe developmental delay at 2 years of age in extremely preterm infants. J Pediatr 160: 395-401.e4, 2012.

32. Cavarsan CF, Gorassini MA and Quinlan KA: Animal models of developmental motor disorders: Parallels to human motor dysfunction in cerebral palsy. J Neurophysiol 122: 1238-1253, 2019.

33. Malaeb S and Dammann OL: Fetal inflammatory response and brain injury in the preterm newborn. J Child Neurol 24: 1119-1126, 2009.

34. Novak I, Morgan C, Adde L, Blackman J, Boyd RN, Brunstrom-Hernandez J, Cioni G, Damiano D, Darrah J, Eliasson AC, et al: Early, accurate diagnosis and early intervention in cerebral palsy: Advances in diagnosis and treatment. JAMA Pediatr 171: 897-907, 2017.

35. Leviton A, Kuban K, O'Shea TM, Paneth N, Fichorova R, Allred EN and Dammann O: The relationship between early concentrations of 25 blood proteins and cerebral white matter injury in preterm newborns: The ELGAN study. J Pediatr 158: 897-903.e1-e5, 2011.

36. Kuban KC, O'Shea TM, Allred EN, Paneth N, Hirtz D, Fichorova RN and Leviton A; ELGAN Study Investigators: Systemic inflammation and cerebral palsy risk in extremely preterm infants. J Child Neurology 29: 1692-1698, 2014.

37. Kadhim H, Tabarki B, Verellen G, De Prez C, Rona AM and Sébire G: Inflammatory cytokines in the pathogenesis of periventricular leukomalacia. Neurology 56: 1278-1284, 2001. 